DOI: 10.12731/2658-6649-2019-11-2-155-166

УДК 616.12-008.331-055.2-036.2

\title{
АНАЛИЗ ЧАСТОТЫ ВСТРЕЧАЕМОСТИ ФАКТОРОВ РИСКА СЕРДЕЧНО-СОСУДИСТЫХ ЗАБОЛЕВАНИЙ СРЕДИ МЕДИЦИНСКИХ РАБОТНИКОВ ПОЖИЛОГО ВОЗРАСТА
}

Деревянных Е.В., Балашова Н.А., Яскевич Р.А., Москаленко О.Л.

Цель. Изучение частоты встречаемости факторов риска (ФР) сердечно-сосудистых заболеваний (ССЗ) среди медичинских работников пожилого возраста

Материалы и методы. Обследовано 105 сотрудников крупной клинической больнииь города Красноярска в возрасте от 60 лет и старше (средний возраст 66 лет). Обследование включало анкетирование, клинические, инструментальные, функииональные и лабораторные методы исследования.

Результаты. Была выявлена близкая к популяционной, высокая частота встречаемости основных факторов риска ССЗ среди медицинских работников пожилого возраста крупной клинической больницы города Красноярска. Изучаемая категория лии, была подвержена курению, злоупотреблению алкоголем, более 70\% обследованных имели избыточную массу тела и свыше одной трети ожирение. Среди них чаще встречались лица с отягощенной наследственностью по СС 3 , в сравнении с лицами молодого и среднего возраста. Полученные данные о частоте встречаемости ФР ССЗ среди медицинских работников пожилого возраста определяют необходимость активного выявления среди них ФР ССЗ и повышения внимания к этой категории лии в ходе диспансеризации, а также пропагандировать здоровый образ жизни (особенно среди лич среднего, младшего и обслуживающего персонала) и тем самым снижать риск тяжелых сердечно-сосудистых заболеваний, таких как инфаркт миокарда и инсульт.

Заключение. Результаты проведенного исследования позволяют сделать выводы о высокой частоте встречаемости ФР ССЗ среди медицинских работников пожилого возраста.

Ключевые слова: медицинские работники; факторы риска; сердечно-сосудистье заболевания; пожилой возраст. 


\section{ANALYSIS OF THE FREQUENCY OF OCCURRENCE OF RISK FACTORS OF CARDIOVASCULAR DISEASES AMONG HEALTH CARE WORKERS IN ELDERLY}

\section{Derevyannich E.V., Balashova N.A., Yaskevich R.A., Moskalenko O.L.}

The purpose of the study. Study of the frequency of occurrence of risk factors for cardiovascular diseases (CVD) among elderly medical professionals.

Materials and methods. 105 employees of a large clinical hospital in the city of Krasnoyarsk aged 60 years and older (average age 66 years) were examined. The examination included questionnaires, clinical, instrumental, functional and laboratory research methods.

Results. A near-population, high frequency of occurrence of the main CVD risk factors was revealed among elderly medical workers of a large clinical hospital in the city of Krasnoyarsk. The studied category of people was exposed to smoking, alcohol abuse, more than $70 \%$ of the examined were overweight and over one third were obese. Among them, people with burdened heredity in CVD were more common in comparison with people of young and middle age. The data on the incidence of CVD risk factors among elderly medical workers determine the need for active identification of CVD risk factors among them and to increase attention to this category of people during the medical examination, as well as to promote a healthy lifestyle (especially among middle, junior and attendant personnel) and most reduce the risk of severe cardiovascular diseases such as myocardial infarction and stroke.

Conclusion. The results of the study allow us to draw conclusions about the high prevalence of CVD risk factors among elderly medical workers.

Keywords: medical workers; risk factors; cardiovascular diseases; old age.

\section{Введение}

Сердечно-сосудистые заболевания (СС3) являются основной причиной заболеваемости, инвалидности и преждевременной смерти в развитых странах, в том числе и в России $[1,11,12,15]$. Сердечно-сосудистые факторы риска (ФР) - это биологические или поведенческие характеристики, повышающие вероятность развития СС3 или смерти $[1,16]$. Согласно данным Всемирной организации здравоохранения (ВО3), поведенческие ФР включают курение, употребление алкоголя, неправильное питание и низкую физическая активность, в то время как к биологическим факто- 
рам риска относят артериальную гипертонию, избыточный вес, ожирение, сахарный диабет и гиперхолестеринемию $[4,16]$. Высокая распространенность этих ФР привела к тому, что ССЗ стали ведущей причиной смертности во всем мире и, следовательно, проблемой общественного здравоохранения $[1,18,19]$. В соответствии с прогнозами ВОЗ, число смертей от ССЗ во всем мире увеличится до 23,4 миллиона к 2030 году [20].

Существует множество основополагающих причин, оказывающих непосредственное влияние на формирование хронических болезней - глобализация, урбанизация, нищета, стресс, а также старение населения. Неуклонное старение населения в развитых странах повышает удельный вес сердечно-сосудистых болезней в общей структуре заболеваемости, что приводит к увеличению количества пожилых пациентов [3, 13, 14].

Опубликованные результаты ряда исследований, проведенных как за рубежом $[17,18,19,20]$, так и в России $[2,8,9]$, целью которых была оценка некоторых аспектов здоровья медицинских работников, продемонстрировали высокую распространенность поведенческих ФР и их неэффективный контроль среди опрошенных работников системы здравоохранения $[5,6,7]$. Именно поэтому состоянию здоровья медицинских работников уделяется повышенное внимание, при этом существующие исследования в основном посвящены изучению распространенности среди медицинского персонала сердечно-сосудистой патологии $[2,6,10]$. В связи с этим большой интерес представляют данные о частоте встречаемости ФР ССЗ у медицинских работников пожилого возраста.

\section{Цель работы}

Изучить частоту встречаемости факторов риска сердечно-сосудистых заболеваний среди медицинских работников пожилого возраста.

\section{Объект и методы исследования}

Объектом исследования были медицинские работники крупной клинической больницы города Красноярска. Всего обследовано 1230 человек в возрасте от 20 до 77 лет, средний возраст 38,5 (95\% ДИ: 37,7 - 39,2) лет. Доля обследуемых лиц в возрасте 60 лет и старше (60-74 года - по классификации ВОЗ (1963)) составила 8,54\% (105 человек), средний возраст 66 (95\%ДИ: 65,24 - 66,9) лет.

В протокол исследования входило: врачебный осмотр, анкетирование, двукратное измерение артериального давления, эхокардиография, электрокардиография, антропометрия, определение биохимических показателей крови. 
В список ФР, которые учитывались при оценке риска сердечно-сосудистых осложнений у больных АГ, включались такие как употребление алкоголя, курение, избыточная масса тела (ИзМТ) и ожирение, возраст старше 55 лет для мужчин 65 лет - для женщин, отягощенная наследственность по сердечно-сосудистым заболеваниям (СС3), дислипидемия.

Статистическая обработка результатов исследования проведена при помощи пакета программ Statistica 6.1. Полученные данные представлены в виде медианы и интерквартильного размаха (Q25 - Q75), в соответствии с их распределением, оцениваемым с помощью критерия Шапиро-Уилка. Для выявления различий между группами, для непрерывных переменных с асимметричным распределением, использован критерий Манна-Уитни. Категориальные переменные сравнивались с помощью критерия $\chi^{2}$ с поправкой Йетса или точного критерия Фишера с двусторонней доверительной вероятностью. Статистически значимыми считали различия при $\mathrm{p}<0,05$.

\section{Результаты и обсуждение}

Анализ частоты встречаемости ФР среди медицинских работников показал, что среди лиц пожилого возраста чаще встречалась ИзМТ $(73,3 \%)$ в сравнении с обследуемыми среднего $\left(67,4 \%, \chi^{2}=1,28, \mathrm{df}=1, \mathrm{p}=0,259\right)$ и молодого возраста $\left(43,9 \%, \chi^{2}=32,4, \mathrm{df}=1, \mathrm{p}=0,001\right)$ (рис. 1$)$. Также отмечались различия по частоте ИзМТ между медицинскими работниками среднего и молодого возраста $\left(\chi^{2}=46,8, \mathrm{df}=1, \mathrm{p}=0,001\right)$.

Подобная картина отмечалась и по частоте встречаемости ожирения: $34,3 \%$ среди пожилого vs $29,1 \%$ среднего возраста $\left(\chi^{2}=0,96, \mathrm{df}=1\right.$, $\mathrm{p}=0,326), 34,3 \%$ среди пожилого vs $15,8 \%$ молодого возраста $\left(\chi^{2}=21,6, \mathrm{df}=1\right.$, $\mathrm{p}=0,001), 29,1 \%$ среднего возраста vs $15,8 \%$ молодого возраста $\left(\chi^{2}=24,2\right.$, $\mathrm{df}=1, \mathrm{p}=0,001)$ соответственно.

По частоте встречаемости курения статистически значимых различий выявлено не было: пожилой vs средний $\left(\chi^{2}=0,39, \mathrm{df}=1, \mathrm{p}=0,533\right)$, пожилой vs молодой $\left(\chi^{2}=0,23, \mathrm{df}=1, \mathrm{p}=0,629\right)$ и средний vs молодой $\left(\chi^{2}=0,72, \mathrm{df}=1\right.$, $\mathrm{p}=0,396)$. Однако в процентном соотношении чаще курили лица молодого возраста $31,9 \%$, и реже пожилого $27,6 \%$ соответственно.

Прием алкоголя как фактор риска отметили $32,4 \%$ обследованных пожилого, $34,8 \%$ молодого и $37,5 \%$ среднего возраста, однако различия не имели статистической значимости: пожилой vs средний $\left(\chi^{2}=0,89, \mathrm{df}=1\right.$, $\mathrm{p}=0,347)$, пожилой vs молодой $\left(\chi^{2}=0,80, \mathrm{df}=1, \mathrm{p}=0,373\right)$ и средний vs молодой $\left(\chi^{2}=0,10, \mathrm{df}=1, \mathrm{p}=0,747\right)$ соответственно. 


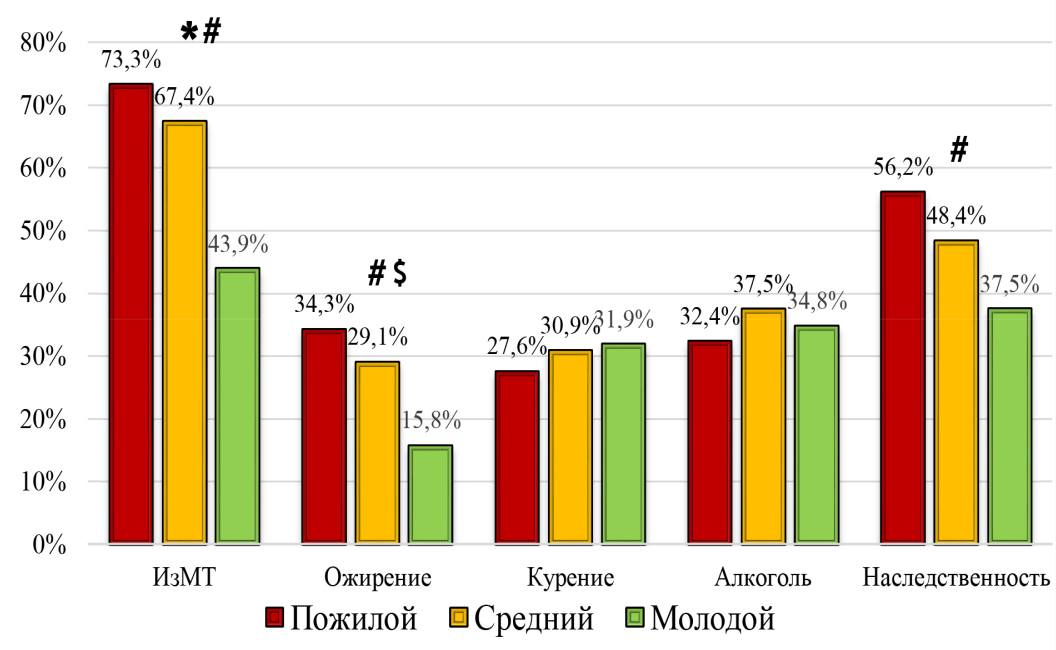

Рис. 1. Факторы риска сердечно-сосудистых заболеваний среди медицинских работников различного возраста.

Примечание:

* - статистически значимые различия между пожилым и средним возрастом $(\mathrm{p}<0,05)$; \# - статистически значимые различия между пожилым и молодым возрастом ( $<<0,05)$; $\$$ - статистически значимые различия между средним и молодым возрастом $(\mathrm{p}<0,05)$.

Среди медицинских работников пожилого возраста чаще встречались лица с отягощенной наследственностью по СС3 $(56,2 \%)$ в сравнении с работниками среднего $\left(48,4 \%, \chi^{2}=1,85, \mathrm{df}=1, \mathrm{p}=0,174\right)$ и молодого возраста $\left(37,5 \%, \chi^{2}=13,6, \mathrm{df}=1, \mathrm{p}=0,001\right)$.

Проведенный анализ частоты встречаемости изучаемых ФР в зависимости от наличия АГ показал, что в изучаемой когорте медицинских работников пожилого возраста частота встречаемости ФР была выше среди лиц с АГ (рис. 2).

Ожирение у лиц с АГ встречалось у $38,8 \%$ обследованных в сравнении с пациентами без $\mathrm{A} \Gamma-32 \%\left(\chi^{2}=1,40, \mathrm{df}=1, \mathrm{p}=0,236\right)$, при этом по частоте встречаемости ИзМТ различия имели статистическую значимость: 78,2\% vs $50 \%\left(\chi^{2}=6,05, \mathrm{df}=1, \mathrm{p}=0,014\right)$. Курение встречалось у $28,7 \%$ vs $22,2 \%$ $\left(\chi^{2}=0,32, \mathrm{df}=1, \mathrm{p}=0,574\right)$, употребление алкоголя у $33,3 \%$ vs $27,8 \%(\chi 2=0,21$, $\mathrm{df}=1, \mathrm{p}=0,647)$ и отягощенная наследственность у $57,5 \%$ vs $50 \%\left(\chi^{2}=0,34\right.$, $\mathrm{df}=1, \mathrm{p}=0,561)$ соответственно. 


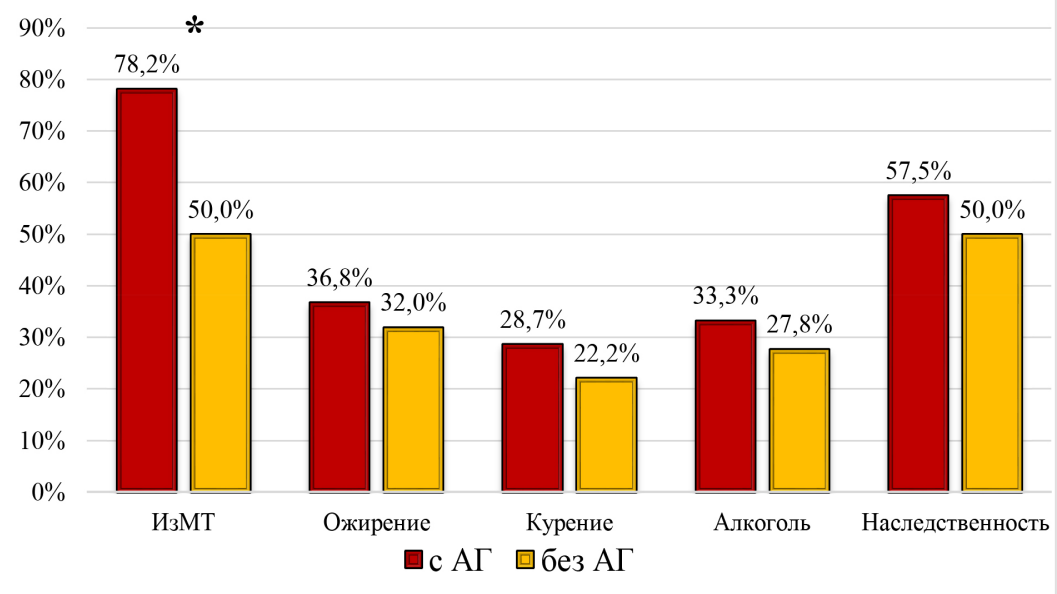

Рис. 2. Частота встречаемости ФР среди медицинских работников пожилого возраста в зависимости от наличия АГ.

Примечание:

* - статистически значимые различия между группами $(\mathrm{p}<0,05)$.

Количественная оценка факторов риска (ФР) среди медицинских работников показала, что лица, не имеющие стратификационных ФР чаще, выявлялись среди обследованных молодого возраста $23,5 \%$, в сравнении со средним $\left(15,1 \%, \chi^{2}=8,87, \mathrm{df}=1, \mathrm{p}=0,003\right)$ и пожилым $\left(8,6 \%, \chi^{2}=12,1, \mathrm{df}=1\right.$, $\mathrm{p}=0,001)$ возрастом (рис. 3).

Схожая картина характерна по наличию 1 ФР: 14,3\% среди пожилого vs $31,9 \%$ среднего возраста $\left(\chi^{2}=12,1, \mathrm{df}=1, \mathrm{p}=0,001\right), 14,3 \%$ среди пожилого vs $39,6 \%$ молодого возраста $\left(\chi^{2}=25,8, \mathrm{df}=1, \mathrm{p}=0,001\right), 31,9 \%$ среднего возраста vs 39,6\% молодого возраста $\left(\chi^{2}=5,39, \mathrm{df}=1, \mathrm{p}=0,020\right)$.

Наличие 2 ФР чаще отмечалось среди лиц среднего возраста, но различия не имели статистической значимости: $30,5 \%$ среди пожилого vs $34 \%$ среднего возраста $\left(\chi^{2}=0,44, \mathrm{df}=1, \mathrm{p}=0,508\right), 30,5 \%$ среди пожилого vs $27,1 \%$ молодого возраста $\left(\chi^{2}=0,52, \mathrm{df}=1, \mathrm{p}=0,471\right), 34 \%$ среднего возраста vs $27,1 \%$ молодого возраста $\left(\chi^{2}=4,92, \mathrm{df}=1, \mathrm{p}=0,027\right)$. Наличие трех ФР чаще отмечалось у работников пожилого возраста: $27,6 \%$ пожилой vs $12,3 \%$ средний возраст ( $\chi^{2}=13,2, \mathrm{df}=1, \mathrm{p}=0,001$ ), 27,6\% пожилой vs $8,6 \%$ молодой возраста $\left(\chi^{2}=35,5, \mathrm{df}=1, \mathrm{p}=0,001\right), 12,3 \%$ средний vs $8,6 \%$ молодой возраст $\left(\chi^{2}=3,40, \mathrm{df}=1, \mathrm{p}=0,065\right)$. 


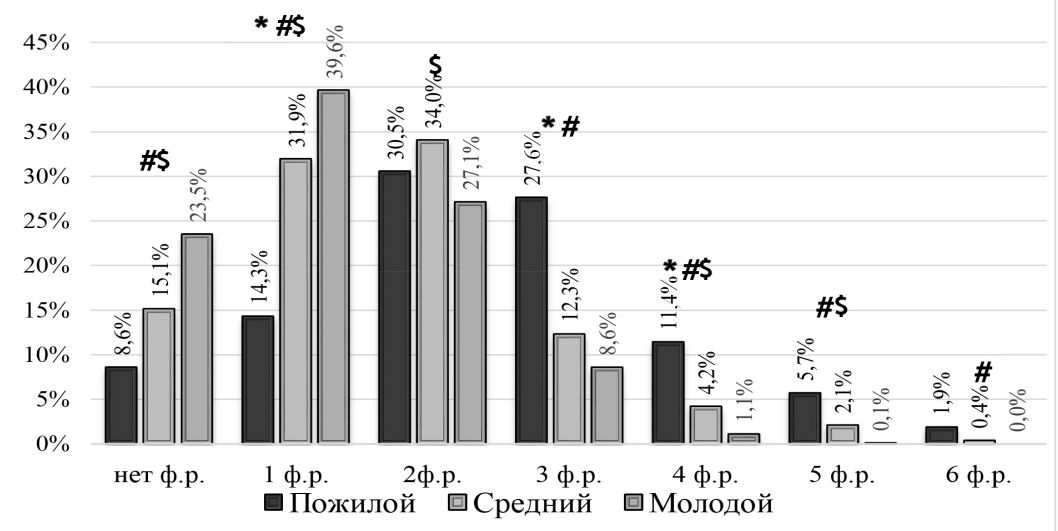

Рис. 3. Количественная оценка факторов риска Примечание: среди медицинских работников различного возраста.

* - статистически значимые различия между пожилым и средним возрастом ( $<<0,05)$; \# - статистически значимые различия между пожилым и молодым возрастом (p<0,05); $\$-$ статистически значимые различия между средним и молодым возрастом $(\mathrm{p}<0,05)$.

Аналогичная картина была среди пациентов с четырьмя ФР: $11,4 \%$ пожилой vs $4,2 \%$ средний возраст ( $\left.\chi^{2}=6,92, \mathrm{df}=1, \mathrm{p}=0,009\right), 11,4 \%$ пожилой vs $1,1 \%$ молодой возраста $\left(\chi^{2}=46,1, \mathrm{df}=1, \mathrm{p}=0,001\right), 4,2 \%$ средний vs $1,1 \%$ молодой возраст $\left(\chi^{2}=11,5, \mathrm{df}=1, \mathrm{p}=0,001\right)$, с пятью ФР: $5,7 \%$ пожилой vs $2,1 \%$ средний возраст $\left(\chi^{2}=3,35, \mathrm{df}=1, \mathrm{p}=0,067\right), 5,7 \%$ пожилой vs $0,1 \%$ молодой возраста $\left(\chi^{2}=39,7, \mathrm{df}=1, \mathrm{p}=0,001\right), 2,1 \%$ средний vs $0,1 \%$ молодой возраст $\left(\chi^{2}=13,6\right.$, $\mathrm{df}=1, \mathrm{p}=0,001)$ и шестью ФР: $1,9 \%$ пожилой vs $0,4 \%$ средний возраст $\left(\chi^{2}=2,43\right.$, $\mathrm{df}=1, \mathrm{p}=0,119), 1,9 \%$ пожилой vs $0 \%$ молодой возраста $\left(\chi^{2}=16, \mathrm{df}=1, \mathrm{p}=0,001\right)$, $0,4 \%$ средний vs $0 \%$ молодой возраст $\left(\chi^{2}=2,95, \mathrm{df}=1, \mathrm{p}=0,086\right)$ соответственно.

Резюмируя вышеизложенное следует отметить, что медицинские работники пожилого возраста имели высокую частоту встречаемости стратификационных ФР в отличии от лиц среднего и молодого возраста, при этом частота встречаемости исследуемых ФР была выше среди лиц с АГ. Медицинские работники пожилого возраста чаще имели 3 и более ФР в сравнении с другими возрастными группами.

\section{Заключение}

Несмотря на достаточно высокую профессиональную информированность, выявлена близкая к популяционной, высокая частота встречаемости 
основных ФР ССЗ среди медицинских работников пожилого возраста крупной клинической больницы города Красноярска. Изучаемая категория лиц, была подвержена курению, злоупотреблению алкоголем, более 70\% обследованных имели избыточную массу тела и свыше одной трети ожирение. Среди них чаще встречались лица с отягощенной наследственностью по ССЗ, в сравнении с лицами молодого и среднего возраста. Полученные данные о частоте встречаемости сердечно-сосудистого риска и связанных с ним факторов среди медицинских работников, в особенности у лиц пожилого возраста, определяют необходимость активного выявления среди них ФР ССЗ, что позволит разработать и оценить эффективность мероприятий, направленных на их снижение и повысить внимание к этой категории лиц в ходе диспансеризации. А также пропагандируя здоровый образ жизни, особенно среди лиц среднего, младшего и обслуживающего персонала, снижать риск тяжелых сердечно-сосудистых заболеваний, таких как инфаркт миокарда и инсульт.

\section{Список литературы}

1. Баланова Ю.А., Концевая А.В., Шальнова С.А. и др. Распространенность поведенческих факторов риска сердечно-сосудистых заболеваний в российской популяции по результатам исследования ЭССЕ-РФ // Профилактическая медицина. 2014. Т. 17, № 5. С. 42-52.

2. Гатиятуллина Л.Л. Состояние здоровья медицинских работников // Вестник современной клинической медицины. 2016. Т. 9, Вып. 3. С. 69-75.

3. Давыдов Е.Л., Ульянова И.О. Медико-социальные аспекты больных артериальной гипертонией в пожилом возрасте // Клиническая геронтология. 2016. T. 22. № 9-10. С. 24-25.

4. Деревянных Е.В., Балашова Н.А., Яскевич Р.А., Москаленко О.Л. Анализ распространенности факторов риска сердечно-сосудистых заболеваний среди мужчин медицинских работников крупной клинической больницы города Красноярска // В мире научных открытий. 2017. Т. 9. № 4. С. 10-33.

5. Деревянных Е.В., Яскевич Р.А., Балашова Н.А. Антропометрические особенности и компонентный состав массы тела у мужчин медицинских работников с артериальной гипертонией // Международный журнал прикладных и фундаментальных исследований. 2016. № 6-2. С. 252-256.

6. Деревянных Е.В., Яскевич Р.А., Балашова Н.А. Возрастные особенности приверженности к лечению артериальной гипертонии у мужчин г. Красноярска // Международный журнал прикладных и фундаментальных исследований. 2016. № 6-1. С. 48-52.

7. Деревянных Е.В., Яскевич Р.А., Балашова Н.А., Москаленко О.Л. Распространенность избыточной массы тела среди женщин медицинских ра- 
ботников крупной клинической больницы города Красноярска // В мире научных открытий. 2016. № 7 (79). С. 26-46.

8. Дубель Е.В., Унгуряну Т.Н. Оценка поведенческих факторов риска медицинских работников многопрофильного стационара // Анализ риска здоровью. 2016. № 2 (14). С. 60-67.

9. Найденова Н.Е., Лобыкина Е.Н. Распространенность факторов риска неинфекционных заболеваний у медицинских работников первичного звена здравоохранения Томской области // Профилактическая медицина. 2015. T.18. № 2. С. 38-42.

10. Неврычева Е.В., Жмеренецкий К.В., Ноздрина Н.С. Здоровье медицинских работников // Здравоохранение Дальнего Востока. 2016. № 1 (67). С. 72-82.

11. Поликарпов Л.С., Прахин Е.И., Хамнагадаев И.И., Эверт Л.С. Онтогенетические особенности формирования атеросклероза // Бюллетень Сибирского отделения Российской академии медицинских наук. 2007. Т. 27. № 5. C. $110-116$.

12. Поликарпов Л.С., Хамнагадаев И.И., Прахин Е.И. и др. Питание и особенности развития атеросклероза у детей и взрослых жителей Севера // Бюллетень Сибирского отделения Российской академии медицинских наук. 2010. T. 30. № 6. С. 129-135.

13. Филимонова Л.А., Борисенко Н.А., Алексеев И.А. и др. Мониторинг качества жизни у пациентов артериальной гипертонии старших возрастных групп // Современные проблемы науки и образования. 2017. № 1. С. 2.

14. Филимонова Л.А., Яскевич Р.А., Давыдов Е.Л. Вопросы формирования и течения артериальной гипертонии в пожилом и старческом возрасте // Сoвременные проблемы науки и образования. 2016. № 6. С. 14.

15. Artyukhov I.P., Grinshtein Y.I., Petrova M.M. et al. Prevalence of arterial hypertension in the Krasnoyarsk Krai (Siberia, Russia) // BMC Cardiovascular Disorders. 2017. Vol.17. P. 138.

16. Bolbrinker J, Zaidi Touis L, Gohlke H, Weisser B, Kreutz R. European guidelines on lifestyle changes for management of hypertension: Awareness and implementation of recommendations among German and European physicians // Herz. 2017 May 22. doi: 10.1007/s00059-017-4575-0.

17. Dayoub E, Jena AB. Chronic Disease Prevalence and Healthy Lifestyle Behaviors Among U.S. Health Care Professionals // Mayo Clinic proceedings. 2015. Vol. 90(12). P. 1659-1662.

18. Gamboa Delgado E.M., Rojas Sánchez L.Z., Bermon Angarita A. et al. Cardiovascular Risk and Its Associated Factors in HealthCare Workers in Colombia: A Study Protocol // JMIR Res. Protoc. 2015. Vol. 30, № 4(3). P. e94. 
19. Lerssrimongkol C., Wisetborisut A., Angkurawaranon C. et al. Active commuting and cardiovascular risk among health care workers // Occup Med (Lond). 2016. Vol. 66(6). P. 483-487.

20. Orozco-González C.N., Cortés-Sanabria L., Viera-Franco J.J. et al. Prevalence of cardiovascular risk factors in a population of health-care workers // Rev. Med. Ins.t Mex. Seguro. Soc. 2016. Vol.54(5). P. 594-60.

\section{References}

1. Balanova Yu.A., Kontsevaya A.V., Shal'nova S.A. et al. Profilakticheskaya meditsina. 2014. V. 17, № 5. P. 42-52.

2. Gatiyatullina L.L. Vestnik sovremennoy klinicheskoy meditsiny. 2016. V. 9, Issue 3. P. 69-75.

3. Davydov E.L., Ul’yanova I.O. Klinicheskaya gerontologiya. 2016. V. 22. № 9-10. P. 24-25.

4. Derevyannykh E.V., Balashova N.A., Yaskevich R.A., Moskalenko O.L. V mire nauchnykh otkrytiy. 2017. V. 9. № 4. P. 10-33.

5. Derevyannykh E.V., Yaskevich R.A., Balashova N.A. Mezhdunarodnyy zhurnal prikladnykh i fundamental'nykh issledovaniy. 2016. № 6-2. P. 252-256.

6. Derevyannykh E.V., Yaskevich R.A., Balashova N.A. Mezhdunarodnyy zhurnal prikladnykh i fundamental'nykh issledovaniy. 2016. № 6-1. P. 48-52.

7. Derevyannykh E.V., Yaskevich R.A., Balashova N.A., Moskalenko O.L. V mire nauchnykh otkrytiy. 2016. № 7 (79). P. 26-46.

8. Dubel' E.V., Unguryanu T.N. Analiz riska zdorov'yu. 2016. № 2 (14). P. 60-67.

9. Naydenova N.E., Lobykina E.N. Profilakticheskaya meditsina. 2015. V.18. № 2. P.38-42.

10. Nevrycheva E.V., Zhmerenetskiy K.V., Nozdrina N.S. Zdravookhranenie Dal’nego Vostoka. 2016. № 1 (67). P. 72-82.

11. Polikarpov L.S., Prakhin E.I., Khamnagadaev I.I., Evert L.S. Byulleten'Sibirskogo otdeleniya Rossiyskoy akademii meditsinskikh nauk. 2007. V. 27. № 5. P. 110-116.

12. Polikarpov L.S., Khamnagadaev I.I., Prakhin E.I. et al. Byulleten'Sibirskogo otdeleniya Rossiyskoy akademii meditsinskikh nauk. 2010. V. 30. № 6. P. 129-135.

13. Filimonova L.A., Borisenko N.A., Alekseev I.A. et al. Sovremennye problemy nauki i obrazovaniya. 2017. № 1. P. 2.

14. Filimonova L.A., Yaskevich R.A., Davydov E.L. Sovremennye problemy nauki i obrazovaniya. 2016. № 6. P. 14.

15. Artyukhov I.P., Grinshtein Y.I., Petrova M.M. et al. Prevalence of arterial hypertension in the Krasnoyarsk Krai (Siberia, Russia). BMC Cardiovascular Disorders. 2017. Vol.17. P. 138.

16. Bolbrinker J, Zaidi Touis L, Gohlke H, Weisser B, Kreutz R. European guidelines on lifestyle changes for management of hypertension: Awareness and im- 
plementation of recommendations among German and European physicians. Herz. 2017 May 22. doi: 10.1007/s00059-017-4575-0.

17. Dayoub E, Jena AB. Chronic Disease Prevalence and Healthy Lifestyle Behaviors Among U.S. Health Care Professionals. Mayo Clinic proceedings. 2015. Vol. 90(12). P. 1659-1662.

18. Gamboa Delgado E.M., Rojas Sánchez L.Z., Bermon Angarita A. et al. Cardiovascular Risk and Its Associated Factors in HealthCare Workers in Colombia: A Study Protocol. JMIR Res. Protoc. 2015. Vol. 30, № 4(3). P. e94.

19. Lerssrimongkol C., Wisetborisut A., Angkurawaranon C. et al. Active commuting and cardiovascular risk among health care workers. Occup Med (Lond). 2016. Vol. 66(6). P. 483-487.

20. Orozco-González C.N., Cortés-Sanabria L., Viera-Franco J.J. et al. Prevalence of cardiovascular risk factors in a population of health-care workers. Rev. Med. Ins.t Mex. Seguro. Soc. 2016. Vol.54(5). P. 594-60.

\section{ДАННЫЕ ОБ АВТОРАХ}

Деревянных Евгений Валерьевич, доцент кафедры пропедевтики внутренних болезней и терапии, кандидат медицинских наук ГБОУ ВПО «КрасГМУ им. проф. Ф.В. Войно-Ясенеикого» МЗ РФ ул. Партизана Железняка, 1а, Красноярск, 660022, Российская Федераџия rusene@mail.ru

Балашова Наталья Арленовна, доцент кафедры пропедевтики внутренних болезней и терапии, кандидат медицинских наук, доцент ГБОУ ВПО «КрасГМУ им. проф. Ф.В. Войно-Ясенеикого» МЗ РФ ул. Партизана Железняка, 1а, Красноярск, 660022, Российская Федераиия balashova-61@mail.ru

Яскевич Роман Анатольевич, доцент кафедры пропедевтики внутренних болезней и терапии, ведущий научный сотрудник группы патологии сердечно-сосудистой системы, кандидат медицинских наук, доцент ГБОУ ВПО «КрасГМУ им. проф. Ф.В. Войно-Ясенецкого» МЗ РФ; Федеральное государственное бюджетное научное учреждение «Научно-исследовательский институт медичинских проблем Севера» ул. Партизана Железняка, 1а, Красноярск, 660022, Российская Федераџия; ул. Партизана Железняка, 32, Красноярск, 660022, Российская Федерация cardio@impn.ru 
Москаленко Ольга Леонидовна, старший научный сотрудник, кандидат биологических наук Федеральное государственное бюджетное научное учреждение «Научно-исследовательский институт медииинских проблем Севера» ул. Партизана Железняка, 32, Красноярск, 660022, Российская Федерация gre-ll@mail.ru

\section{DATA ABOUT THE AUTHORS}

Derevyannich Evgeny Valeryevich, associate professor at department of propedeutics of internal diseases and therapy, candidate of medical science Krasnoyarsk State Medical University named after Professor V.F. VoinoYasenetzkiy

1a, P. Zheleznyaka St., Krasnoyarsk, 660022, Russian Federation rusene@mail.ru

Balashova Natalia Arlenovna, associate professor at department of propedeutics of internal diseases and therapy, candidate of medical science, docent Krasnoyarsk State Medical University named after Professor V.F. VoinoYasenetzkiy

1a, P. Zheleznyaka St., Krasnoyarsk, 660022, Russian Federation balashova-61@mail.ru

Yaskevich Roman Anatolyevich, associate professor at department of propedeutics of internal diseases and therapy, leading researcher of the group pathology of the cardiovascular system, candidate of medical science, docent Krasnoyarsk State Medical University named after Professor V.F. VoinoYasenetzkiy; Federal State Budgetary Scientific Institution «Scientific Research Institute of medical problems of the North» 1a, P. Zheleznyaka St., Krasnoyarsk, 660022, Russian Federation; 3g, P. Zheleznyaka St., Krasnoyarsk, 660022, Russian Federation cardio@impn.ru

Moskalenko Olga Leonidovna, Senior Researcher, Candidate of Biological Sciences

Federal State Budgetary Scientific Institution «Scientific Research Institute of medical problems of the North»

3g, P. Zheleznyaka St., Krasnoyarsk, 660022, Russian Federation gre-ll@mail.ru 